Article

\title{
Presence of Helicobacter Species in Gastric Mucosa of Human Patients and Outcome of Helicobacter Eradication Treatment
}

\author{
Rita Matos ${ }^{1,2,3,+}{ }^{\mathbb{D}}$, Emily Taillieu ${ }^{4,+}{ }^{\mathbb{D}}$, Sofie De Bruyckere ${ }^{4}$, Chloë De Witte ${ }^{4} \mathbb{D D}$, Alexandra Rêma ${ }^{3}$, \\ Hugo Santos-Sousa ${ }^{1,5,6}$, Jorge Nogueiro ${ }^{5,6} \mathbb{D}^{\mathbb{D}}$, Celso A. Reis ${ }^{1,2,3,6} \mathbb{D}_{\text {, Fátima Carneiro }}{ }^{1,6,7} \mathbb{D}^{\mathbb{D}}$, \\ Freddy Haesebrouck $4, \ddagger\left(\mathbb{D}\right.$, Irina Amorim ${ }^{1,2,3, *, \ddagger(\mathbb{D})}$ and Fátima Gärtner $1,2, \ddagger$ (D)
}

check for updates

Citation: Matos, R.; Taillieu, E.; De Bruyckere, S.; De Witte, C.; Rêma, A.; Santos-Sousa, H.; Nogueiro, J.; Reis, C.A.; Carneiro, F.; Haesebrouck, F.; et al. Presence of Helicobacter Species in Gastric Mucosa of Human Patients and Outcome of Helicobacter Eradication Treatment. J. Pers. Med. 2022, 12, 181. https://doi.org/ 10.3390/jpm12020181

Academic Editor: Matthew Cooke

Received: 14 December 2021

Accepted: 24 January 2022

Published: 29 January 2022

Publisher's Note: MDPI stays neutral with regard to jurisdictional claims in published maps and institutional affiliations.

Copyright: (C) 2022 by the authors. Licensee MDPI, Basel, Switzerland. This article is an open access article distributed under the terms and conditions of the Creative Commons Attribution (CC BY) license (https:// creativecommons.org/licenses/by/ $4.0 /)$.
1 Instituto de Investigação e Inovação em Saúde (i3S), Universidade do Porto, 4200-135 Porto, Portugal; ritam@ipatimup.pt (R.M.); h.santos.sousa@gmail.com (H.S.-S.); celsor@ipatimup.pt (C.A.R.); fcarneiro@ipatimup.pt (F.C.); fgartner@ipatimup.pt (F.G.)

2 Institute of Pathology and Molecular Immunology, University of Porto (IPATIMUP), 4200-135 Porto, Portugal

3 Instituto de Ciências Biomédicas Abel Salazar, Universidade of Porto (ICBAS), 4050-313 Porto, Portugal; alexandra.rema@gmail.com

4 Department of Pathobiology, Pharmacology and Zoological Medicine, Faculty of Veterinary Medicine, Ghent University, 9000 Ghent, Belgium; Emily.Taillieu@UGent.be (E.T.); Sofie.DeBruyckere@UGent.be (S.D.B.); Chloe.DeWitte@UGent.be (C.D.W.); Freddy.Haesebrouck@UGent.be (F.H.)

5 Serviço de Cirurgia Geral, Centro Hospitalar Universitário São João, 4200-319 Porto, Portugal; nogueiro.jorge@gmail.com

6 Faculty of Medicine, University of Porto (FMUP), 4200-319 Porto, Portugal

7 Serviço de Anatomia Patológica, Centro Hospitalar Universitário São João, 4200-319 Porto, Portugal

* Correspondence: iamorim@ipatimup.pt

+ Shared first authorship.

$\ddagger$ Shared senior authorship.

\begin{abstract}
The genus Helicobacter is composed of bacteria that colonize both the human and animal gastrointestinal tract. Helicobacter pylori infects half of the world's population, causing various disorders, such as gastritis, duodenitis and gastric cancer. Additionally, non-Helicobacter pylori Helicobacter species (NHPH) are commonly found in the stomach of pigs, dogs and cats. Most of these species have zoonotic potential and prevalence rates of $0.2-6.0 \%$, and have been described in human patients suffering from gastric disorders undergoing a gastric biopsy. The aim of this study was to determine the occurrence of Helicobacter spp. in the stomach of patients with gastric cancer ( $n=17)$ and obese $(n=63)$ patients. Furthermore, the outcome of the Helicobacter eradication treatment and the current infection status was evaluated. Overall, based on the genus-specific PCR followed by sequencing, DNA from Helicobacter spp. was detected in $46.3 \%$ of the patients, including single infections with $H$. pylori in $43.8 \%$ of the patients and mixed infections with $H$. pylori and canineor feline-associated H. felis in $2.5 \%$. About $32.5 \%$ of the patients had been subjected to previous Helicobacter eradication therapy and the triple standard therapy was the most frequent scheme (42.3\%). In $48.0 \%$ of the patients who received eradication treatment, bacteria were still detected, including one mixed infection. In $23.1 \%$ of the patients who reported that a subsequent test had been performed to confirm the elimination of the bacteria, Helicobacter were still detected. In conclusion, although in a smaller percentage, NHPH may also be present in the human stomach. Thus, specific NHPH screening should be included in the diagnostic routine. The continued presence of $H$. pylori in the stomach of patients recently subjected to eradication schemes raises questions about the efficacy of the current Helicobacter treatments.
\end{abstract}

Keywords: Helicobacter; NHPH; human stomach; gastric disease; eradication treatment

\section{Introduction}

The Helicobacter genus consists of a group of Gram-negative, motile bacteria, colonizing the stomach and intestinal tract of humans and animals [1]. Helicobacter pylori (H. pylori) 
is the most common gastric Helicobacter species, with an average worldwide prevalence of $58 \%$, and is considered a major public health issue [2-4]. Infection is usually acquired during childhood, and although the majority of the individuals remain asymptomatic, some develop gastric disorders, of which chronic gastritis is the most frequently described pathology $[1,2,4,5]$. In the majority of the cases, the gastritis is superficial, but progression to gastric or duodenal ulcers (10-20\%) and/or gastric (adeno)carcinoma (1-2\%) can also occur $[4,5]$. As such, H. pylori is considered a Group I carcinogen by the International Agency for Research on Cancer $[4,6,7]$. Multiple studies have shown that $H$. pylori eradication reduces gastric inflammation, thereby (i) preventing the progression towards pre-malignant lesions, (ii) decreasing the incidence of gastric carcinoma [7-9], and [10] improving corpus gastritis and dysplasia lesions [10]. Nevertheless, treatment efficacy has been declining in the last decade due to several factors such as side effects, including increasing antimicrobial resistance and the high costs of the antibiotic treatments [11].

Besides H. pylori, other gastric helicobacters, named non-Helicobacter pylori helicobacters (NHPH), have been described colonizing both the human and animal stomach [12-15]. So far, $H$. suis, $H$. heilmannii, $H$. ailurogastricus, $H$. felis, $H$. salomonis and $H$. bizzozeronii have been detected in human patients [1,16-19]. The infection rate, however, is significantly lower compared to $H$. pylori, with reported rates of $0.2-6.0 \%$ in human patients suffering from gastric complains undergoing a gastric biopsy [17]. Nevertheless, these values may be an underestimation of the true prevalence, considering the lack of proper diagnostic tools [17].

Human gastric NHPH infection is usually accompanied by gastritis, antral erosions and duodenal ulcers $[1,17,20]$. Furthermore, NHPH infection has also been associated with gastric low-grade mucosa-associated lymphoid tissue (MALT) lymphoma, and the risk of developing this disease is higher than that with $H$. pylori infection [21]. Human infections with NHPH most likely originate from direct or indirect contact with infected animals. Living in close proximity with animals is therefore considered a major risk factor. Besides frequency, the intensity of animal contact is also important. Indeed, a higher incidence of these infections has been noted in farmers, staff of slaughterhouses, pet owners and children having intense contact with pets. Other transmission routes might be consumption of contaminated water and, for H. suis, consumption of contaminated pork [22-24]. Recent studies also demonstrated that patients infected with NHPH may be co-infected with H. pylori and/or another gastric Helicobacter species [12,25].

H. pylori infection rate is related to socioeconomic status, level of urbanization, sanitation, access to clean water and hygiene levels. This may explain why higher numbers of cases have been reported in developing countries (almost $80.0 \%$ on Africa), compared with low levels in developed countries (p.e. 24.4\% on Oceania) [3]. At the individual level, several risk factors for $H$. pylori infection have been proposed, including older age, smoking, untreated water intake, alcohol and salty food consumption, and family history of gastric disorders [26]. It can be concluded that the disease outcome of Helicobacter spp. infection is a result of a complex interaction between host, environmental and bacterial factors [4].

In Europe, the overall prevalence of Helicobacter is around $47.0 \%$, but in Portugal it can be as high as $86.4 \%$ [3]; for this reason, this country was selected for this study. Therefore, the aims of this research were: (1) to determine the occurrence of gastric Helicobacter species in a subset of patients treated at Hospital de São João, Porto, Portugal; and (2) to describe the outcome of the Helicobacter eradication treatment in those patients, and to determine their current Helicobacter infection status.

\section{Materials and Methods}

\subsection{Patients Samples}

Gastric samples were collected from Portuguese patients who underwent gastric resection as a treatment for gastric cancer (GC) $(n=17)$ or who underwent laparoscopic sleeve gastrectomy for morbid obesity $(\mathrm{OB})(n=63)$. In patients diagnosed with $\mathrm{GC}$, two samples were collected, one from tumor tissue and one of adjacent tissue. In OB patients, 
three samples were collected from the gastric body/fundus region. Regardless of the origin, each specimen was divided in two fragments: one was fixed in $10 \%$ formalin for histological evaluation and the other was immediately frozen at $-80{ }^{\circ} \mathrm{C}$ for further molecular studies. Samples were collected between March 2017 and July 2020, from surgeries at Centro Hospitalar Universitário de São João (CHUSJ), Porto, Portugal. All the patients included in the study were informed about the project and their written consent was requested. During the pre-surgical consultation, the medical doctor performed a small and anonymous survey, concerning personal details (age and gender), information regarding putative animal contact (frequency and type of animals), and evidence of a possible Helicobacter eradication treatment carried out in the 18 months prior to the gastric surgery. Information regarding the Helicobacter eradication treatment was confirmed with the clinical report from the hospital. None of the participants were considered vulnerable individuals. All the procedures were approved by the Ethics Committee from the CHSJ/FMUP (CES 127-15).

\subsection{Histological Analysis of Helicobacter Species in Human Gastric Samples}

Samples were fixed in $10 \%$ phosphate-buffered formalin and embedded in paraffin. Serial sections of $3 \mu \mathrm{m}$ were made, both for haematoxylin-eosin (H\&E) staining for histopathological evaluation and for immunohistochemical examination.

Sections stained with H\&E were examined by a pathologist in order to confirm the gastric anatomical region. Additionally, a modified-Giemsa (MG) stain was performed to assist in the identification of Helicobacter spp. The bacterial density colonization was quantified according to the following classification: - , absence of organisms; + , few organisms $(<10$ organisms $/ 400 \times) ;++$, moderate number of organisms $(10$ to 50 organisms $/ 400 \times)$; +++ , large number of organisms ( $>50$ organisms $/ 400 \times$ ), as previously described [27].

\subsection{Immunohistochemical Detection of Helicobacter Species in Human Gastric Samples}

For the immunohistochemical (IHC) study, sections were deparaffinized, hydrated, and antigen retrieval was performed in $10 \mathrm{mmol} / \mathrm{L}$ sodium citrate buffer ( $\mathrm{pH}$ 6.0, $10 \mathrm{~min}$ ). Slides were cooled for $20 \mathrm{~min}$ at room temperature and rinsed twice in phosphate buffered saline with $0.05 \%$ Tween 20 (PBS-T $0.05 \%$ ) for $5 \mathrm{~min}$. After blocking endogenous peroxidase with 3\% hydrogen peroxide in methanol for $10 \mathrm{~min}$, slides were blocked for 30 min with normal goat serum (Dako, Santa Clara, CA, USA), diluted 1:5 in 10\% bovine serum albumin (BSA $10 \%$ ). Thereafter, slides were incubated overnight at $4{ }^{\circ} \mathrm{C}$ with a primary polyclonal antiserum against H. pylori (RBK012; Zytomed, Berlin, Germany), diluted 1:150 in BSA 5\%, known to present immunoreactivity with a wide range of bacteria belonging to the Helicobacter genus [28]. Sections were rinsed with PBS-T 0.05\% and incubated with secondary antibody goat anti-rabbit diluted 1:200 in BSA 5\%, for 30 min (Dako, Santa Clara, CA, USA). Slides were rinsed again and incubated with avidin-biotin-peroxidase complex solution for 30 min (Vectastain ${ }^{\circledR}$ Elite ABC HRP Kit, PK-6100, Vector Laboratories, Burlingame, CA, USA). Colour was developed with 3,3 $\alpha$-diamino-benzidine (DAB; Sigma, St. Louis, $\mathrm{MO}$, USA) for 5 to $7 \mathrm{~min}$ at room temperature. Sections were then counterstained with haematoxylin, dehydrated and mounted. Slides were observed at light microscopy and positive immunoreactivity was recorded as a distinct golden-brown labelling of the bacteria located at mucosal surface, in gastric pits or glands and in parietal cells. Again, the amount of bacteria was evaluated according to the same classification described on the section above [27].

\subsection{DNA Extraction and Helicobacter Species Identification through PCR Analysis}

Cryopreserved gastric samples were homogenized, and DNA was extracted using the ExtractMe DNA Tissue Plus Kit (EM04, Blirt, Gdańsk, Poland), according to the manufacturer instructions.

The primers Hcom1 and Hcom2 (Table S1) were used to amplify a 390-bp fragment of the $16 S$ rRNA gene sequence to determine the presence of bacteria belonging to the Helicobactergenus [29-31]. PCR was performed in reaction volumes of $20 \mu \mathrm{L}$ containing $1.5 \mathrm{mM}$ 
$\mathrm{MgCl}_{2}$ (Promega), 1x GoTaq ${ }^{\circledR}$ Flexi PCR buffer (Promega, Madison, WI, USA), $200 \mu \mathrm{M}$ deoxynucleotide triphosphates (dNTPs) (Bioline, Meridian Bioscience, Ohio, USA), $0.5 \mu \mathrm{M}$ forward primer, $0.5 \mu \mathrm{M}$ reverse primer, $1 \mathrm{U}$ GoTaq ${ }^{\circledR}$ Flexi DNA polymerase (Promega) and $1 \mu \mathrm{L}$ of the DNA extract. PCR amplification was performed under the following conditions: 5 min of preincubation at $94{ }^{\circ} \mathrm{C}$, followed by 40 cycles of 1 min at $94{ }^{\circ} \mathrm{C}, 1 \mathrm{~min}$ at $63^{\circ} \mathrm{C}$, and $1 \mathrm{~min}$ at $72{ }^{\circ} \mathrm{C}$. A final extension was performed for $5 \mathrm{~min}$ at $72{ }^{\circ} \mathrm{C}$. As a positive control, DNA extracted from a pure culture of $H$. suis (HS5) was used [32].

Helicobacter species-specific PCR assays were performed for $H$. suis, H. bizzozeronii, H. felis, H. salomonis, H. heilmannii, H. ailurogastricus and H. pylori. The primers used for each Helicobacter species-specific PCR and the respective amplification conditions are listed in Table S1. PCR was performed in reaction volumes of $20 \mu \mathrm{L}$ containing $2.5 \mathrm{mM}$ $\mathrm{MgCl} 2$ (Promega), 1x GoTaq ${ }^{\circledR}$ Flexi PCR buffer (Promega, Madison, WI, USA), $200 \mu \mathrm{M}$ deoxynucleotide triphosphates (dNTPs) (Bioline), $0.5 \mu \mathrm{M}$ forward primer, $0.5 \mu \mathrm{M}$ reverse primer, $0.6 \mathrm{U}$ GoTaq ${ }^{\circledR}$ Flexi DNA polymerase (Promega), and $1 \mu \mathrm{L}$ of the DNA extract. DNA extracted from a pure culture of $H$. suis (HS5) was used as the positive control.

Five microlitres of each PCR amplification product was analysed through gel electrophoresis in 1.5\% agarose (AGRMP-RO Roche, Merck KGaA, Darmstadt, Germany) in TBE buffer (VWR Life Science, Amsterdam, The Netherlands). GeneRuler 100bp Plus DNA Ladder (Thermo Scientific ${ }^{\mathrm{TM}}$ SM0323) was used as a weight marker. Images were acquired on a UV transilluminator (UVP PhotoDoc-it Imaging Systems, Fisher Scientific, Hampton, $\mathrm{NH}$, USA).

Sequencing analysis of samples showing a positive PCR result upon genus- and/or species-specific PCR was performed in order to confirm the Helicobacter species present. Sequencing analysis of amplicons positive for Helicobacter genus-specific PCR allows discrimination between $H$. suis, canine- and feline-associated gastric NHPH as a group, and $H$. pylori. Sequencing was done at Eurofins Genomics ${ }^{\circledR}$ (Edersberg, Germany). All obtained sequences were processed using the BioNumerics ${ }^{\circledR}$ software (version 7.6.3, Applied Maths, Sint-Martens-Latem, Belgium). Finally, the aligned sequences were blasted using the NCBI Nblast tool (https:/ /blast.ncbi.nlm.nih.gov/Blast.cgi; last accessed on 12 May 2021). A cut-off value of $96 \%$ was used for average nucleotide identity as a threshold for species delineation [33].

A patient was considered positive in the case that at least one of the samples taken was positive in at least one of the PCR assays, followed by a confirmatory sequencing result (not based on histology results).

\section{Results}

\subsection{Patients Data}

A total of 221 gastric samples belonging to 80 patients were evaluated in this study, comprising 34 samples obtained from 17 GC patients and 187 samples from 63 OB patients. The mean age was $50.9 \pm 14.8$ years $(72.5 \pm 10.0$ for the GC patients and $45.1 \pm 9.6$ for the OB patient). The female:male ratio for the overall patients evaluated was 1.8:1.

\subsection{Histological and Immunohistochemical Detection of Helicobacter Species in Human Gastric Samples}

Histological analysis using $\mathrm{H} \& \mathrm{E}$ staining confirmed the presence of malignant epithelial neoplasia in tissue fragments from GC patients, while gastric samples from OB patients showed no signs of neoplastic transformation.

Based on the MG stain, bacteria were detected in 43 out of 80 patients (53.8\%). In more detail, Helicobacter spp.-like organisms were visualized in 7 out of 17 GC patients $(41.2 \%)$ and in 36 out of $63 \mathrm{OB}$ patients (57.1\%) (Table 1). These organisms were mainly identified within the mucus layer and close to the superficial gastric epithelium (Figure 1A-D). The results of histological and immunohistochemical analysis are presented on Figure 1 and Table 1. 
Table 1. Occurrence of Helicobacter species in human gastric samples, based on different technical approaches (MG: modified-Giemsa stain; IHC: immunohistochemistry; PCR: polymerase chain reaction). Detailed information about each patient is present in Table S2.

\begin{tabular}{cccccc}
\hline \multirow{2}{*}{ Gastric Samples } & \multicolumn{2}{c}{$\begin{array}{c}\text { Detection Methods } \\
\text { Positive (Percentage and } \\
\text { Number) }\end{array}$} & IHC & $\begin{array}{c}\text { Genus-Specific } \\
\text { PCR + Sequencing }\end{array}$ & \multicolumn{2}{c}{ Species-Specific PCR + Sequencing } \\
\cline { 2 - 7 } & MG & H. pylori & H. felis \\
\hline Total $(n=80)$ & $53.8 \%(43 / 80)$ & $66.3 \%(53 / 80)$ & $46.3 \%(37 / 80)$ & $21.3 \%(17 / 80)$ & $2.5 \%(2 / 80)$ \\
\hline $\begin{array}{c}\text { Gastric cancer patients } \\
(n=17)\end{array}$ & $41.2 \%(7 / 17)$ & $52.9 \%(9 / 17)$ & $11.8 \%(2 / 17)$ & $11.8 \%(2 / 17)$ & - \\
\hline Obese patients $(n=63)$ & $57.1 \%(36 / 63)$ & $69.8 \%(44 / 63)$ & $55.5 \%(35 / 63)$ & $23.8 \%(15 / 63)$ & $3.2 \%(2 / 63)$ \\
\hline
\end{tabular}
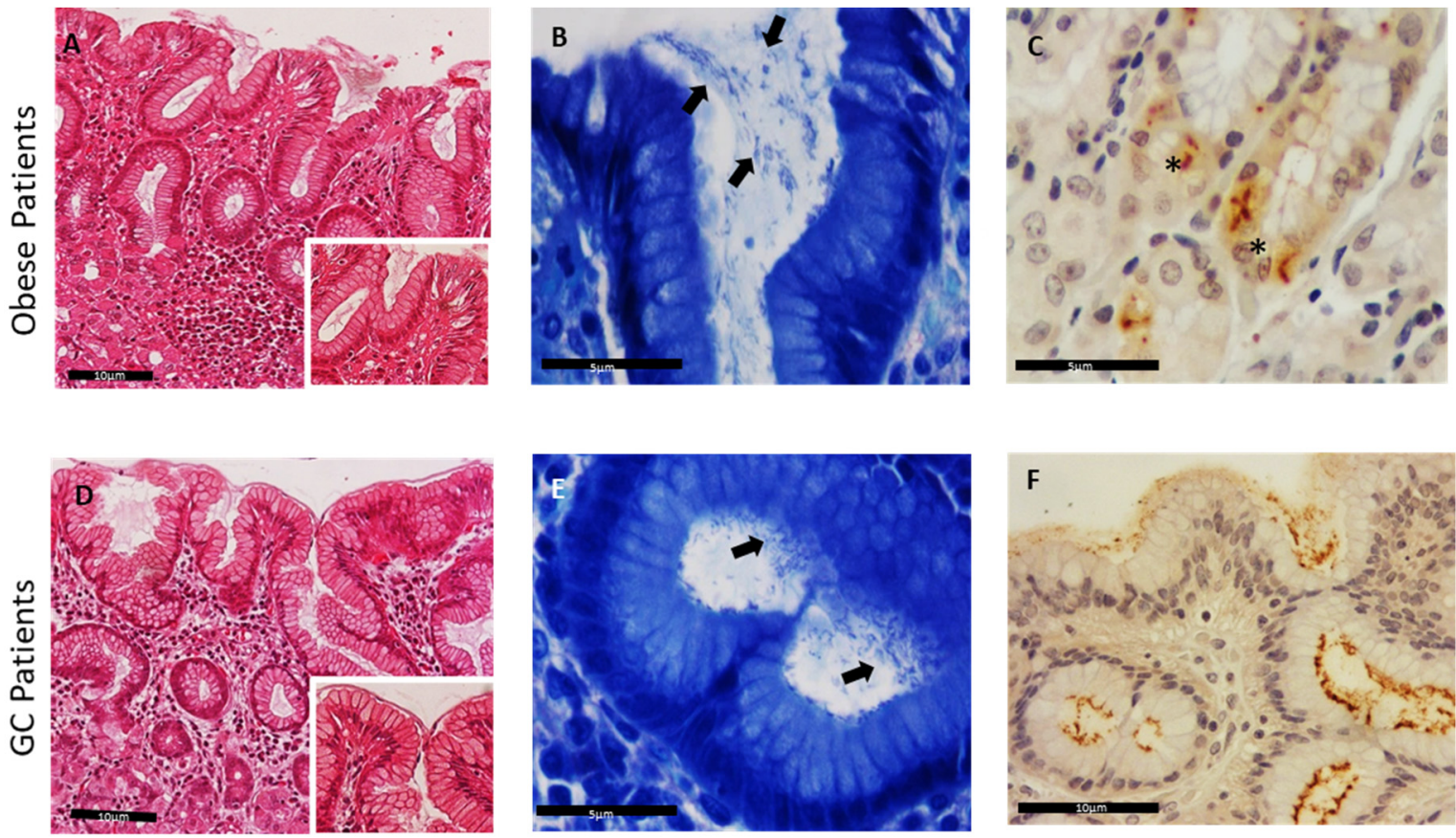

Figure 1. Detection of Helicobacter species in human gastric mucosa sections. H\&E stain of gastric sections from obese (OB) patients (A) and gastric cancer (GC) patients (D), 200× and 400× (inset). Modified-Giemsa stain, highlighting bacteria at the epithelium surface and gastric crypts (black arrows), in obese patients (B) and GC patients (E), magnification $600 \times$. (C,F) Helicobacter spp. immunopositivity within the superficial mucus, in the lumen of gastric deep glands, $400 \times$, and inside parietal cells, $600 \times,\left({ }^{*}\right)$ in obese patients $(C)$ and GC patients $(\mathbf{F})$.

Using IHC, curve- or spiral-shaped bacteria were identified in 53 out of 80 patients $(66.3 \%)$. In the GC cases, Helicobacter spp. immunopositivity was detected in 9 of the 17 patients $(52.9 \%)$, while in the remaining 8 , no specific nor compatible immunoreactivity was identified (47.1\%). Among the samples of OB patients, Helicobacter spp. immunopositivity was detected in 44 out of 63 patients (69.8\%), whereas 19 individuals were considered negative $(30.2 \%)$. Both MG stain and IHC technique allowed the identification of bacteria, not only when they were present in smaller amounts $(+/++)$, but also when present in more discrete locations such as the lumen of deeper glands and the cytoplasm of parietal cells (Figure 1, Table 1). 


\subsection{Detection of Helicobacter Species}

Helicobacter genus-specific PCR was performed in all human gastric samples, followed by sequencing of the positive amplicons in order to discriminate between $\mathrm{H}$. suis, H. pylori and the group of canine- and feline-associated gastric NHPH. PCR results were positive in 75 samples (33.9\%), of which one proved false positive based on sequencing analysis of the amplicon and the remaining 74 were classified as $H$. pylori. This corresponded to presence of H. pylori in at least one sample of 37 out of 80 patients (46.3\%) (Tables 1 and S2). These included 2 out of 17 GC patients (11.8\%) and 35 out of 63 OB patients (55.5\%).

Species-specific PCR assays for H. suis, H. bizzozeronii, H. felis, H. salomonis, H. heilmannii, $H$. ailurogastricus and $H$. pylori were performed in all human gastric samples, again followed by sequencing of the positive amplicons in order to confirm presence of the Helicobacter species in question. In 30 samples (13.6\%), PCR results for $H$. pylori were found positive, of which one proved false positive based on sequencing analysis of the amplicon, while in the remaining 29, the presence of $H$. pylori was confirmed. This corresponded to presence of $H$. pylori in at least one sample of 17 out of $80(21.3 \%)$ (Tables 1 and S2), with the majority of these patients belonging to the OB group (15 patients, $23.8 \%$ ), and two patients belonging to the GC group (11.8\%). All samples found positive based on the species-specific PCR assay for $H$. pylori were also found positive for $H$. pylori based on the genus-specific PCR assay. As for H. suis, two samples $(0.9 \%)$ were found to be positive, with the PCR result again confirmed by sequencing analysis of the amplicon. These two samples belonged to two different patients (2.5\%) in whom the presence of $H$. pylori was also detected based on the genus-specific PCR assay and who belong to the OB group (2 out of $63 ; 3.2 \%$ ). Results of all other species-specific PCR assays performed were negative.

Comparisons between the different techniques used for the identification of gastric Helicobacter species demonstrated that 24 patients $(30.0 \%)$ were positive in all the techniques used (MG, IHC and PCR + sequencing). On the other hand, in 24 other patients $(30.0 \%)$ a positive result was obtained with MG or IHC, but the samples were negative for genus- and/or species-specific PCR. Furthermore, six patients (7.5\%) were positive with PCR + sequencing, and negative with other techniques used.

Detailed results are listed in Tables 1 and S2.

There was no correlation between gender and presence of Helicobacter species in this cohort of patients.

\subsection{Association between Helicobacter spp. Presence and Animal Contact}

Among the 80 patients included in the study, 68 answered the survey $(85.0 \%)$, of which 13 belong to the GC group (13 out of $17 ; 76.5 \%$ ) and 55 to the OB group ( 55 out of $63 ; 87.3 \%$ ). Close contact with animals was referred to by 55 patients (80.9\%), comprising 11 out of 13 GC $(84.6 \%)$ and 44 out of $55 \mathrm{OB}$ patients $(80.0 \%)$. The great majority of the respondents classified the contact with pets as a regular and daily basis $(51 / 55 ; 92.7 \%)$. Close contact with dogs and cats was mentioned by 8 out of 11 GC patients $(72.7 \%)$ and 43 out of $44 \mathrm{OB}$ patients $(97.7 \%)$. Contact with other animals, such as chickens, rabbits, parakeets, sheep, etc., was also mentioned by $34.5 \%$ of the patients, including 6 out of $11 \mathrm{GC}(54.5 \%)$ and 13 out of $44 \mathrm{OB}$ patients $(29.5 \%)$.

All the information obtained from the inquiries is resumed in Figure 2.

\subsection{Helicobacter spp. Presence in Patients with Previous History of Eradication Treatment}

Information regarding previous Helicobacter eradication therapy in the last 18 months was collected, both from the surveys and clinical reports. Results indicated that 26 out of 80 patients $(32.5 \%)$ were subjected to eradication treatment, 51 out of $80(63.8 \%)$ did not receive any treatment, and for three patients $(3.7 \%)$, this information was not available (Figures 3 and 4). 


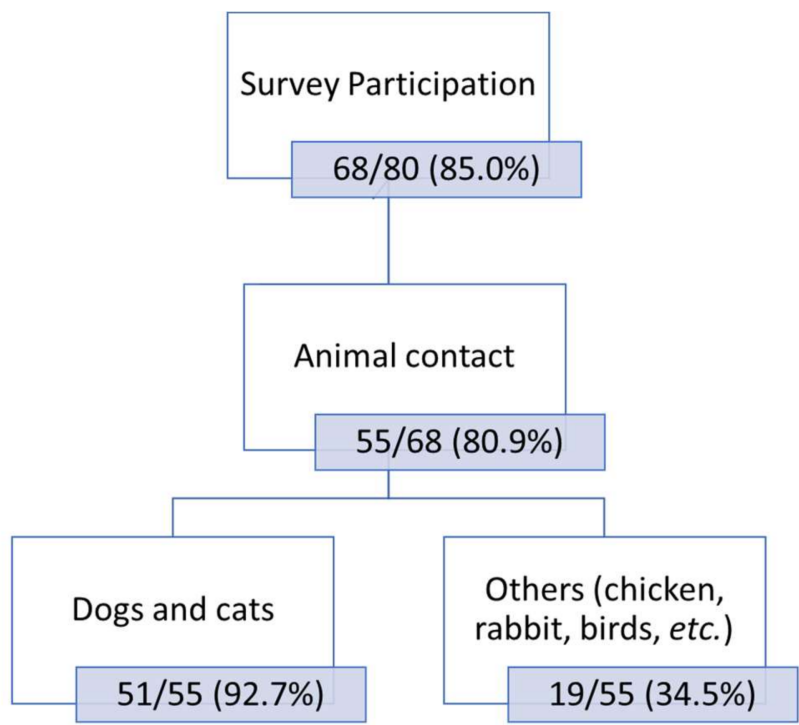

Figure 2. Overall results of the animal contact based on the patients' surveys.

A

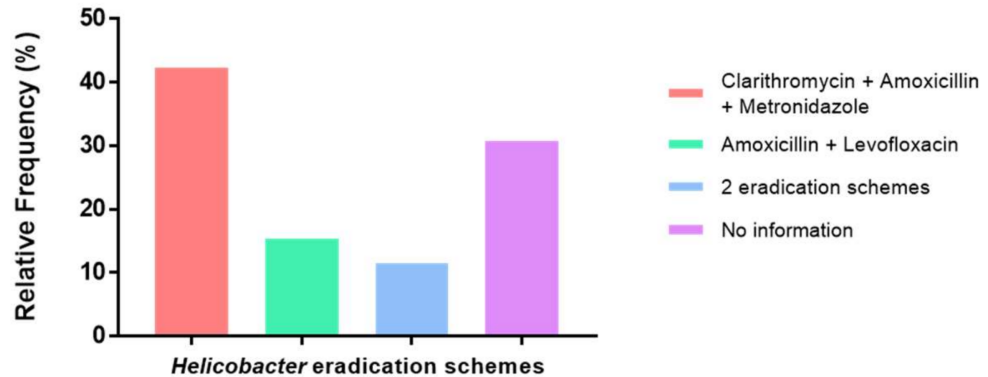

B

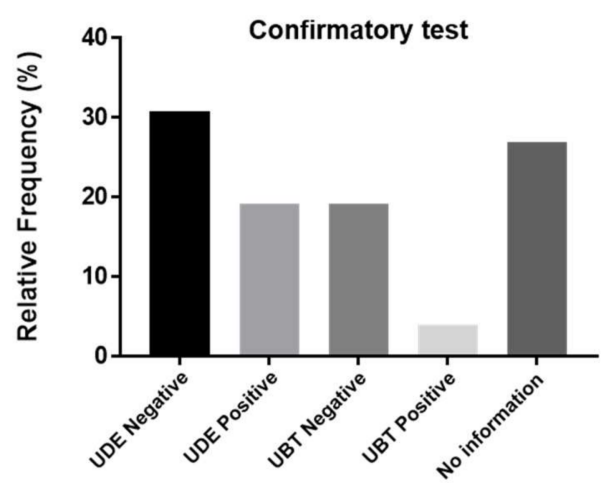

Figure 3. Helicobacter eradication treatment. (A) Detailed information about the therapeutical schemes used. (B) Confirmatory test performed to evaluate the presence of Helicobacter organisms after eradication treatment. UDE: upper digestive endoscopy; UBT: urea breath test.

Regarding the Helicobacter eradication scheme, the triple standard therapy (proton pump inhibitor (PPI), metronidazole, clarithromycin/amoxicillin) was the most common scheme performed (11 out of 26;42.3\%). Amoxicillin and levofloxacin were used in 4 out of 26 patients $(15.4 \%)$, and three patients $(11.5 \%)$ were subjected to two different Helicobacter eradication protocols (first with the triple standard therapy and later with amoxicillin and levofloxacin). For the remaining eight patients, there was no information available regarding the treatment performed (Figure 3). 


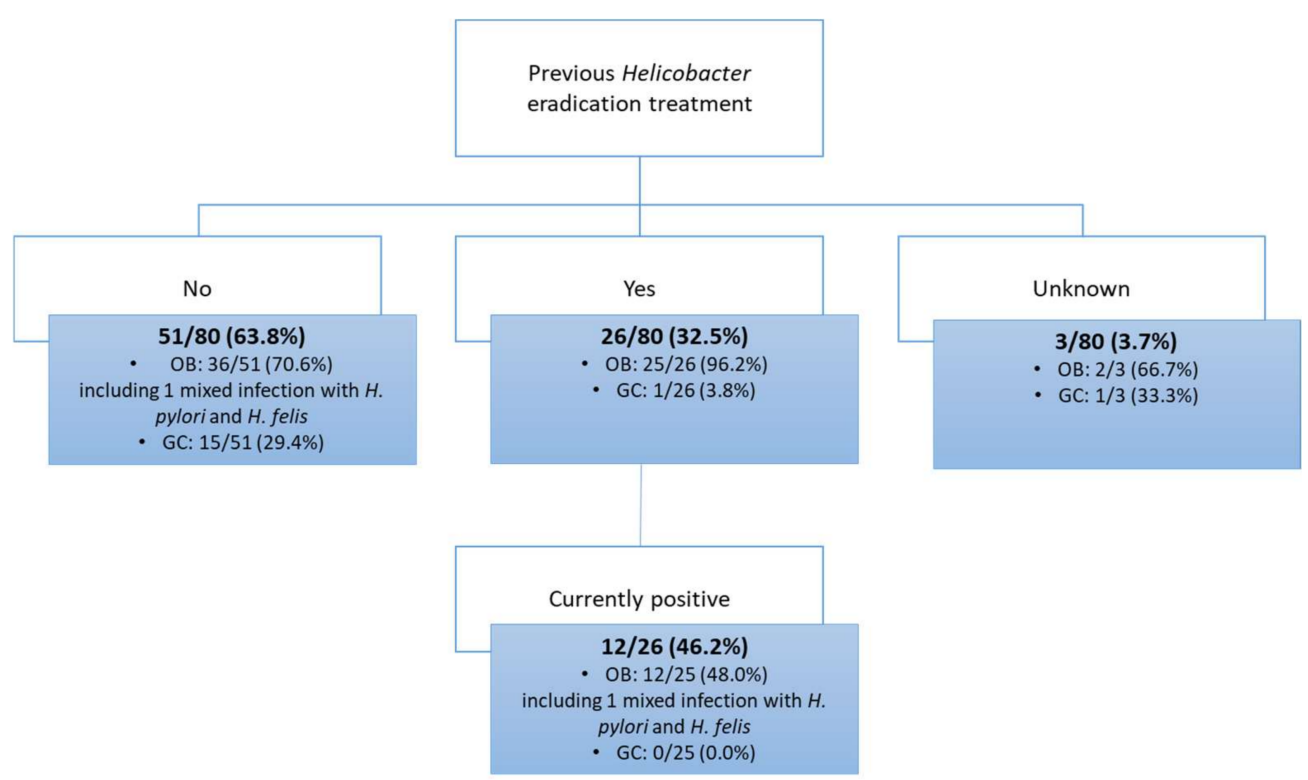

Figure 4. Information about the Helicobacter eradication treatment and the current infectious status.

The patients subjected to the eradication treatment belonged predominantly to the OB group ( 25 out of 26 patients; $96.2 \%$ ). Amongst these 25 patients, results indicated that Helicobacter organisms were still detected in 12 individuals (48.0\%). Based on genusand species-specific PCR and sequencing of the amplicon, a mixed infection with two Helicobacter spp. (H. pylori + H. felis) was found in one of those 12 patients (Figures 3 and 4). The other OB patient presenting a mixed infection with $H$. pylori and $H$. felis was not subjected to any Helicobacter eradication scheme in the 18 months prior to the gastric surgery.

In the GC group, only one patient out of 26 received an eradication treatment prior to surgery $(3.8 \%)$, and in this particular individual no Helicobacter DNA was detected.

For 26 out of 80 patients $(32.5 \%)$, a confirmatory test was also performed after the eradication treatment, either by urea breath test (UBT) (6 out of 26; $23.1 \%$ ) or using other methods (upper digestive endoscopy (UDE) (13 out of 26; 50.0\%)). For those evaluated through UBT, five individuals (19.2\%) were negative for urease-producing organisms and only 1 out of 26 was positive (3.9\%) (Figure 3). The UDE screening demonstrated that 8 out of $26(30.8 \%)$ patients were negative for Helicobacter, while in 5 out of 26 individuals $(19.2 \%)$, the bacteria were still detected by species-specific PCR followed by sequencing of the amplicon. For seven individuals $(26.9 \%)$, there was information that a confirmatory test was performed, but the result was not mentioned.

All the information is presented in Figures 3 and 4.

\section{Discussion}

In this study, human gastric samples were collected from $17 \mathrm{GC}$ and $63 \mathrm{OB}$ patients and screened for the presence of Helicobacter spp. Since Helicobacter organisms are not easily visualized with H\&E, two additional staining techniques, namely MG and IHC, were used to highlight their presence $[27,28]$. The percentage of Helicobacter-positive patients based solely on MG and IHC analysis was $53.8 \%$ and $66.3 \%$, respectively. Based on the IHC analysis, bacteria were identified in the mucus layer and superficial gastric epithelium, as well as within deep glans and even in the cytoplasm of the gastric parietal cells. The canaliculi of parietal cells are characterized by an extreme acidic $\mathrm{pH}$ due to the secretion of hydrochloric acid, that could lead to possible unspecific immunoreactivity of the antibody used in IHC. The use of electronic microscopy could be a good approach to confirm the presence of Helicobacter species inside the parietal cells, although this was not performed in our study. It has been suggested that $H$. pylori may present an intracellular location representing one of the few bacteria able to invade the host cell membrane, and being 
internalized in gastric epithelial or immune cells [34]. Interestingly, the presence of NHPH inside parietal cells was already described in the canine and feline gastric mucosa and it was thought that this phenomenon was an exclusive feature of NHPH $[28,35,36]$. Although IHC does not allow differentiation between the different gastric Helicobacter spp., in most patients only H. pylori was detected through PCR. This indicates that H. pylori could also be able to invade parietal cells. Intracellular localization might be a strategy used by the bacteria to evade to the immune system, and to resist to the eradication treatment.

On the other hand, higher sensitivity for Helicobacter spp. detection using molecular techniques, such as PCR, is recognized [37] allowing the identification of the bacteria at the genus or species level, depending on the primers used [27]. In our study, Helicobacter genus-specific PCR followed by sequencing revealed the presence of $H$. pylori DNA in $46.3 \%$ of the patients, while this was only verified in $21.3 \%$ with the species-specific PCR assay for $H$. pylori. This suggests that the sensitivity of the species-specific PCR assay used here is lower than that of the genus-specific assay in regard of $H$. pylori detection. This could be due to many reasons, such as: (1) not yet identified/uncultured NHPH species with high similarity to $H$. pylori are being detected with the genus-specific PCR; and/or (2) some of the already identified NHPH species showing a high genome similarity to $H$. pylori, for which we did not perform a species-specific PCR, can give some false positive results.

In contrast, our results showed a lower detection of Helicobacter species through PCR in comparison to MG or IHC. This can be explained by the high specificity of the molecular techniques. The genus- and species-specific PCR followed by sequencing of the positive amplicons is a more accurate and precise technique for identification of these Helicobacter species showing high similarity. On the other hand, the identification based only on histological techniques can lead to false positive results since it depends on human evaluation and screening, and other bacterial species can also be stained and interfere with the result. Furthermore, with these techniques we cannot identify the bacteria at species level, which is why the PCR followed by sequencing was considered the best strategy for the detection of bacterial DNA in the human gastric samples. To this end, herein, a conventional Helicobacter genus-specific PCR assay was conducted based on the 16S rRNA gene which was able to discriminate between $\mathrm{H}$. suis, $\mathrm{H}$. pylori and the group of canineand feline-associated gastric NHPH upon sequencing, in addition to species-specific PCR analysis for H. suis, H. bizzozeronii, H. felis, H. salomonis, H. heilmannii, H. ailurogastricus and H. pylori.

Infection of the human gastric mucosa with $H$. pylori leads to chronic inflammation, characterized by infiltration of neutrophils and macrophages $[4,7,38,39]$. The density of bacterial colonization by $H$. pylori is reported to be high in the initial steps of infection, but it decreases during the disease progression, being almost devoid of organisms in late stages of cancer transformation that are characterized by a marked increase of Lactobacillus composition $[40,41]$. However, even in these extreme conditions, $H$. pylori was able to survive and persist, being detected in $11.8 \%$ of the GC patients. Regarding the OB group, H. pylori was found in $55.5 \%$ of the patients and we can hypothesize that this high rate can be related to less extreme gastric microenvironment conditions in comparison to those patients suffering from gastric carcinoma. Furthermore, based on species-specific PCR followed by sequencing of the amplicon, two patients exhibited mixed infections with two Helicobacter species, namely H. pylori and the canine- and feline-associated $\mathrm{H}$. felis (2.5\%), confirming that mixed infections with $H$. pylori and animal-associated and zoonotic gastric NHPH may occur [12,25].

Although these patients did not present any clinical alteration besides the obesity condition, histopathological analysis demonstrated that the majority presented signs of hyperplasia of the superficial epithelium, gastritis and presence of multiple lymphoid follicles (data not shown). These findings could be related with the presence of H. pylori [42].

The low rate of NHPH occurrence $(2.5 \%)$ goes towards the values described in the literature [17]. Amongst the patients who answered the survey, the great majority reported a close and frequent contact with different animal species (80.9\%). Interestingly, one of the 
patients presenting mixed infection with $H$. pylori and $H$. felis, referred to a close contact with a cat as a pet, while the other patient reported no contact with animals. These results confirm that contact with pets does not necessarily result in a NHPH infection, raising questions about how humans get infected with these Helicobacter species.

The efficacy of the Helicobacter eradication treatment has been declining in the past decade, due to several factors such as side effects, increasing antibiotic resistant strains, and the cost of the antibiotic regimens [11]. Acquired resistance to antibiotics has been described not only for H. pylori, but also for some NHPH isolates, such as H. heilmannii, $H$. ailurogastricus and $H$. suis $[13,15]$. Since these bacteria can be found in the stomach of several animals and also in humans, the presence of acquired resistance to some antimicrobial compounds can have an impact both on human and veterinary health. Among the 80 individuals included in this study, 32.5\% were subjected to eradication treatment in the last 18 months. Remarkably, in $46.2 \%$ of these patients, Helicobacter spp. (including one of the patients with a mixed $H$. pylori $+H$. felis infection) were still detected in gastric tissues. There are several factors that might explain this finding: (1) the treatment was not strictly carried out by the patient (incomplete or unfinished) or was not effective at all; (2) the treatment was carried out too close to the confirmatory test, so there had not yet been an opportunity for the bacteria to be completely eliminated; or (3) the patient was reinfected after the treatment. Among the patients who remained Helicobacter-positive after treatment, the triple standard therapy was the most frequent scheme, followed by treatment with a combination of amoxicillin and levofloxacin; some patients were even submitted to two different eradication schemes. After the eradication treatment, patients should be submitted to a confirmatory test, either by urea breath test or by other techniques that usually require endoscopy to confirm the elimination of the bacteria. Previously performed confirmatory tests indicated a negative Helicobacter result in four patients, that later were found infected with $H$. pylori (through PCR and confirmed by sequencing), which calls into question the efficacy of the treatment.

Portugal has been considered one the countries with the highest resistance percentage to clarithromycin $(42.35 \%)$, one of the main antibiotics that constitute the standard triple therapy [43]. This could partially justify the relative low efficiency of the eradication protocol, since $42.3 \%$ of the patients were submitted to a therapeutical scheme based on this drug.

Additionally, limitations of the study have to be taken into account. Different surgical approaches were used to collect the gastric samples according to the type of patients (cancer vs. obese) which may have influenced the results obtained. Addition of a control group would certainly benefit comparisons and statistical analysis. Moreover, with respect to Helicobacter spp. eradication treatment, the results described were due to different therapeutical schemes using different drugs, and part of the information herein obtained was based on the testimony and memory of the patients themselves.

\section{Conclusions}

In conclusion, the current results confirm that mixed infections with at least two $\mathrm{He}$ licobacter spp. can occur in humans. Therefore, it can be advised to test for the presence of $H$. pylori as well as gastric NHPH. Additionally, due to the decreased efficiency of the current Helicobacter eradication treatment, the development of new therapeutical strategies is necessary.

Supplementary Materials: The following supporting information can be downloaded at: https: / / www.mdpi.com/article/10.3390/jpm12020181/s1. Table S1: Oligonucleotide primers used for PCR amplification. Table S2: Different approaches for Helicobacter species detection in human gastric samples (Sequencing, modified-Giemsa stain, IHC, PCR). 


\begin{abstract}
Author Contributions: Conceptualization, I.A., F.G. and F.H.; methodology, R.M., E.T., S.D.B. and A.R.; sample collection, H.S.-S., J.N. and F.C.; validation, I.A., F.G. and F.H.; writing-original draft preparation, R.M., E.T. and I.A.; writing-review and editing, R.M., E.T., C.D.W., F.C., C.A.R., F.H., F.G. and I.A.; supervision, I.A., F.H. and F.G. All authors have read and agreed to the published version of the manuscript.
\end{abstract}

Funding: R.M. is funded by Fundação para a Ciência e Tecnologia/Ministério da Ciência, Tecnologia e Inovação (FCT) PhD scholarship SFRH/BD/131159/2017.

Institutional Review Board Statement: The study was conducted according to the guidelines of the Ethics Committee from the Centro Hospitalar Universitário de São João/Faculdade de Medicina da Universidade do Porto (CHSJ/FMUP) (CES 127-15).

Informed Consent Statement: Written informed consent was obtained from all subjects involved in the study.

Conflicts of Interest: The authors declare no conflict of interest.

\title{
References
}

1. Bahadori, A.; De Witte, C.; Agin, M.; De Bruyckere, S.; Smet, A.; Tümgör, G.; Gökmen, T.G.; Haesebrouck, F.; Köksal, F. Presence of gastricHelicobacterspecies in children suffering from gastric disorders in Southern Turkey. Helicobacter 2018, 23 , e12511. [CrossRef] [PubMed]

2. Doulberis, M.; Srivastava, S.; Polyzos, S.A.; Kountouras, J.; Papaefthymiou, A.; Klukowska-Rötzler, J.; Blank, A.; Exadaktylos, A.K.; Srivastava, D.S. Active Helicobacter pylori Infection is Independently Associated with Nonalcoholic Steatohepatitis in Morbidly Obese Patients. J. Clin. Med. 2020, 9, 933. [CrossRef] [PubMed]

3. Hooi, J.K.Y.; Lai, W.Y.; Ng, W.K.; Suen, M.M.Y.; Underwood, F.E.; Tanyingoh, D.; Malfertheiner, P.; Graham, D.Y.; Wong, V.W.S.; Wu, J.C.Y.; et al. Global Prevalence of Helicobacter pylori Infection: Systematic Review and Meta-Analysis. Gastroenterology 2017, 153, 420-429. [CrossRef] [PubMed]

4. Van Amsterdam, K.; van Vliet, A.; Kusters, J.G.; Van Der Ende, A. Of microbe and man: Determinants of Helicobacter pylori-related diseases. FEMS Microbiol. Rev. 2006, 30, 131-156. [CrossRef]

5. Blaser, N.; Backert, S.; Pachathundikandi, S.K. Immune Cell Signaling by Helicobacter pylori: Impact on Gastric Pathology. Helicobacter Pylori Hum. Dis. 2019, 1149, 77-106. [CrossRef]

6. Blaecher, C.; Smet, A.; Flahou, B.; Pasmans, F.; Ducatelle, R.; Taylor, D.; Weller, C.; Bjarnason, I.; Charlett, A.; Lawson, A.J.; et al. Significantly higher frequency of Helicobacter suis in patients with idiopathic parkinsonism than in control patients. Aliment. Pharmacol. Ther. 2013, 38, 1347-1353. [CrossRef]

7. $\quad$ Rodrigues, M.F.; Guerra, M.R.; De Alvarenga, A.V.R.; Souza, D.Z.D.O.; Costa, R.A.V.E.S.; Cupolilo, S.M.N. Helicobacter pylori infection and gastric cancer precursor lesions: Prevalence and associated factors in a reference laboratory in southeastern brazil. Arq. Gastroenterol. 2019, 56, 419-424. [CrossRef]

8. Cai, X.; Carlson, J.; Stoicov, C.; Li, H.; Wang, T.C.; Houghton, J. Helicobacter felis eradication restores normal architecture and ihnibits gastric cancer progression in C57BL/6 mice. Gastroenterology 2005, 128, 1937-1952. [CrossRef]

9. Yang-Ou, Y.-B.; Hu, Y.; Zhu, Y.; Lu, N.-H. The effect of antioxidants on Helicobacter pylori eradication: A systematic review with meta-analysis. Helicobacter 2018, 23, e12535. [CrossRef]

10. De Briyne, N.; Atkinson, J.; Borriello, S.P.; Pokludová, L. Antibiotics used most commonly to treat animals in Europe. Vet. Rec. 2014, 175, 325. [CrossRef]

11. De, R.; Kundu, P.; Swarnakar, S.; Ramamurthy, T.; Chowdhury, A.; Nair, G.B.; Mukhopadhyay, A.K. Antimicrobial Activity of Curcumin against Helicobacter pylori Isolates from India and during Infections in Mice. Antimicrob. Agents Chemother. 2009, 53, 1592-1597. [CrossRef] [PubMed]

12. Bento-Miranda, M.; Figueiredo, C. Helicobacter heilmannii sensu lato: An overview of the infection in humans. World J. Gastroenterol. 2014, 20, 17779-17787. [CrossRef] [PubMed]

13. Berlamont, H.; Smet, A.; De Bruykere, S.; Boyen, F.; Ducatelle, R.; Haesebrouck, F.; De Witte, C. Antimicrobial susceptibility pattern of Helicobacter suis isolates from pigs and macaques. Vet. Microbiol. 2019, 239, 108459. [CrossRef]

14. De Witte, C.; Taminiau, B.; Flahou, B.; Hautekiet, V.; Daube, G.; Ducatelle, R.; Haesebrouck, F. In-feed bambermycin medication induces anti-inflammatory effects and prevents parietal cell loss without influencing Helicobacter suis colonization in the stomach of mice. Vet. Res. 2018, 49, 35. [CrossRef]

15. Matos, R.; De Witte, C.; Smet, A.; Berlamont, H.; De Bruyckere, S.; Amorim, I.; Gärtner, F.; Haesebrouck, F. Antimicrobial Susceptibility Pattern of Helicobacter heilmannii and Helicobacter ailurogastricus Isolates. Microorganisms 2020, 8, 957. [CrossRef]

16. Boyanova, L.; Koumanova, R.; Lazarova, E.; Jelev, C. Helicobacter pylori and Helicobacter heilmannii in children. A Bulgarian study. Diagn. Microbiol. Infect. Dis. 2003, 46, 249-252. [CrossRef]

17. Haesebrouck, F.; Pasmans, F.; Flahou, B.; Chiers, K.; Baele, M.; Meyns, T.; Decostere, A.; Ducatelle, R. Gastric Helicobacters in Domestic Animals and Nonhuman Primates and Their Significance for Human Health. Clin. Microbiol. Rev. 2009, 22, 202-223. [CrossRef] 
18. Sykora, J.; Hejda, V.; Varvarovská, J.; Stozicky, F.; Gottrand, F.; Siala, K. Helicobacter heilmannii Related Gastric Ulcer in Childhood. J. Pediatric Gastroenterol. Nutr. 2003, 36, 410-413. [CrossRef]

19. Yakoob, J.; Abbas, Z.; Khan, R.; Naz, S.; Ahmad, Z.; Islam, M.; Awan, S.; Jafri, F.; Jafri, W. Prevalence of non Helicobacter pylori species in patients presenting with dyspepsia. BMC Gastroenterol. 2012, 12, 3. [CrossRef]

20. Joosten, M.; Lindén, S.; Rossi, M.; Tay, A.C.Y.; Skoog, E.; Padra, M.; Peters, F.; Perkins, T.; Vandamme, P.; Van Nieuwerburgh, F.; et al. Divergence between the Highly Virulent Zoonotic Pathogen Helicobacter heilmannii and Its Closest Relative, the LowVirulence "Helicobacter ailurogastricus" sp. nov. Infect. Immun. 2016, 84, 293-306. [CrossRef]

21. Morgner, A.; Lehn, N.; Andersen, L.P.; Thiede, C.; Bennedsen, M.; Trebesius, K.; Neubauer, B.; Neubauer, A.; Stolte, M.; Bayerdörffer, E. Helicobacter heilmannii-Associated Primary Gastric Low-Grade MALT Lymphoma: Complete Remission After Curing the Infection. Gastroenterology 2000, 118, 821-828. [CrossRef]

22. De Cooman, L.; Flahou, B.; Houf, K.; Smet, A.; Ducatelle, R.; Pasmans, F.; Haesebrouck, F. Survival of Helicobacter suis bacteria in retail pig meat. Int. J. Food Microbiol. 2013, 166, 164-167. [CrossRef] [PubMed]

23. De Cooman, L.; Houf, K.; Smet, A.; Flahou, B.; Ducatelle, R.; De Bruyne, E.; Pasmans, F.; Haesebrouck, F. Presence of Helicobacter suis on pork carcasses. Int. J. Food Microbiol. 2014, 187, 73-76. [CrossRef] [PubMed]

24. Joosten, M.; Blaecher, C.; Flahou, B.; Ducatelle, R.; Haesebrouck, F.; Smet, A. Diversity in bacterium-host interactions within the species Helicobacter heilmannii sensu stricto. Vet. Res. 2013, 44, 65. [CrossRef]

25. Liu, J.; He, L.; Haesebrouck, F.; Gong, Y.; Flahou, B.; Cao, Q.; Zhang, J. Prevalence of Coinfection with Gastric Non-Helicobacter pylori Helicobacter(NHPH) Species in Helicobacter pylori-infected Patients Suffering from Gastric Disease in Beijing, China. Helicobacter 2014, 20, 284-290. [CrossRef]

26. Borges, S.S.; Ramos, A.F.P.L.; Filho, A.V.D.M.; Braga, C.A.D.S.B.; Carneiro, L.C.; Barbosa, M.S. [Article partial retraction] prevalence of helicobacter pylori infection in dyspeptic patients and its association with clinical risk factors for developing gastric adenocarcinoma. Arq. Gastroenterol. 2019, 56, 66-70. [CrossRef]

27. Prachasilpchai, W.; Nuanualsuwan, S.; Chatsuwan, T.; Techangamsuwan, S.; Wangnaitham, S.; Sailasuta, A. Diagnosis of Helicobacter spp. infection in canine stomach. J. Vet. Sci. 2007, 8, 139-145. [CrossRef]

28. Amorim, I.; Smet, A.; Alves, O.; Teixeira, S.; Saraiva, A.L.; Taulescu, M.; Reis, C.; Haesebrouck, F.; Gärtner, F. Presence and significance of Helicobacter spp. in the gastric mucosa of Portuguese dogs. Gut Pathog. 2015, 7, 1-8. [CrossRef]

29. Choi, Y.K.; Han, J.H.; Joo, H.S. Identification of Novel Helicobacter Species in Pig Stomachs by PCR and Partial Sequencing. J. Clin. Microbiol. 2001, 39, 3311-3315. [CrossRef]

30. Farshad, S.; Alborzi, A.; Hosseini, S.A.M.; Oboodi, B.; Rasouli, M.; Japoni, A.; Nasiri, J. Identification of Helicobacter pylori DNA in Iranian patients with gallstones. Epidemiol. Infect. 2004, 132, 1185-1189. [CrossRef]

31. Farshad, S.; Alborzi, A.; Malekhosseini, S.A.; Gramizadeh, B.; Oboodi, B.; Rasouli, M.; Japoni, A.; Kalani, M.; Pourabbas, B. Detection of Helicobacter DNA in Bile Samples of Patients with Biliary Diseases Living in South of Iran. IJMS 2006, 31, 186-190.

32. Baele, M.; Decostere, A.; Vandamme, P.; Ceelen, L.; Hellemans, A.; Mast, J.; Chiers, K.; Ducatelle, R.; Haesebrouck, F. Isolation and characterization of Helicobacter suis sp. nov. from pig stomachs. Int. J. Syst. Evol. Microbiol. 2008, 58, 1350-1358. [CrossRef] [PubMed]

33. Praet, J.; Cnockaert, M.; Meeus, I.; Smagghe, G.; Vandamme, P. Gilliamella intestini sp. nov., Gilliamella bombicola sp. nov., Gilliamella bombi sp. nov. and Gilliamella mensalis sp. nov.: Four novel Gilliamella species isolated from the bumblebee gut. Syst. Appl. Microbiol. 2017, 40, 199-204. [CrossRef]

34. Dubois, A.B.T. Helicobacter pylori is invasive and it may be a facultative intracellular organism. Cell Microbiol. 2007, 9, 1108-1116. [CrossRef] [PubMed]

35. Scanziani, E.S.K.; Monestiroli, S.; Soldati, S.; Strauss-Ayali, D.; Del Piero, F. Histological and immunohistochemical detection of different Helicobacter species in the gastric mucosa of cats. J. Vet. Diagn. Investig. 2001, 13, 3-12. [CrossRef] [PubMed]

36. Wiinberg, B.S.A.; Dietz, H.H.; Egelund, T.; Greiter-Wilke, A.; McDonough, S.P.; Olsen, J.; Priestnall, S.; Chang, Y.F.; Simpson, K.W. Quantitative Analysis of Inflammatory and Immune Responses in Dogs with Gastritis and Their Relationship to Helicobacter spp. Infection. J. Vet. Intern. Med. 2005, 19, 4-14. [CrossRef] [PubMed]

37. Chung, T.-H.; Kim, H.-D.; Lee, Y.-S.; Hwang, C.-Y. Determination of the Prevalence of Helicobacter heilmannii-Like Organisms Type 2 (HHLO-2) Infection in Humans and Dogs Using Non-Invasive Genus/Species-Specific PCR in Korea. J. Vet. Med. Sci. 2014, 76, 73-79. [CrossRef]

38. Carneiro, F.; Chaves, P. Pathologic Risk Factors of Adenocarcinoma of the Gastric Cardia and Gastroesophageal Junction. Surg. Oncol. Clin. N. Am. 2006, 15, 697-714. [CrossRef]

39. Lee, Y.-C.; Chiang, T.-H.; Chou, C.-K.; Tu, Y.-K.; Liao, W.-C.; Wu, M.-S.; Graham, D.Y. Association Between Helicobacter pylori Eradication and Gastric Cancer Incidence: A Systematic Review and Meta-analysis. Gastroenterology 2016, 150, $1113-1124$. [CrossRef]

40. Dicksved, J.; Lindberg, M.; Rosenquist, M.; Enroth, H.; Jansson, J.; Engstrand, L. Molecular characterization of the stomach microbiota in patients with gastric cancer and in controls. J. Med. Microbiol. 2009, 58, 509-516. [CrossRef]

41. Noto, J.M.; Peek, R.M., Jr. The gastric microbiome, its interaction with Helicobacter pylori, and its potential role in the progression to stomach cancer. PLoS Pathog. 2017, 13, e1006573. [CrossRef] [PubMed] 
42. Dixon, M.F.; Genta, R.M.; Yardley, J.H.; Correa, P. Classification and grading of gastritis. The updated Sydney System. International Workshop on the Histopathology of Gastritis, Houston 1994. Am. J. Surg. Pathol. 1996, 20, 1161-1181. [CrossRef] [PubMed]

43. Ghotaslou, R.; Leylabadlo, H.E.; Asl, Y.M. Prevalence of antibiotic resistance in Helicobacter pylori: A recent literature review. World J. Methodol. 2015, 5, 164-174. [CrossRef] [PubMed] 